\title{
The Breaking Span of Thick and Hard Roof Based on the Thick Plate Theory and Strain Energy Distribution Characteristics of Coal Seam and Its Application
}

\author{
Xiaolong Li, ${ }^{1,2}$ Changwu Liu, ${ }^{1,2}$ Yang Liu, $^{3}$ and Hui Xie ${ }^{4}$ \\ ${ }^{1}$ State Key Laboratory of Hydraulic and Mountain River Engineering, Sichuan University, Chengdu 610065, China \\ ${ }^{2}$ School of Hydraulic and Hydroelectric Engineering, Sichuan University, Chengdu 610065, China \\ ${ }^{3}$ School of Civil Engineering, Anhui Jianzhu University, Hefei 230022, China \\ ${ }^{4}$ Sichuan Electric Power Design \& Consulting Co., Ltd., Chengdu 610041, China
}

Correspondence should be addressed to Changwu Liu; liucw2016@stu.scu.edu.cn

Received 31 March 2017; Accepted 7 August 2017; Published 13 September 2017

Academic Editor: Alessandro Tasora

Copyright (C) 2017 Xiaolong Li et al. This is an open access article distributed under the Creative Commons Attribution License, which permits unrestricted use, distribution, and reproduction in any medium, provided the original work is properly cited.

\begin{abstract}
In mining engineering, the thick and hard roof threatens the safe production. Based on Reissner plate theory and combined with weighted residual method, with four edges clamped as the boundary conditions, this paper deduces the theoretical formula of the first breaking span of thick and hard roof. Based on Vlasov plate theory, with four edges simply supported as the boundary conditions, this paper deduces the theoretical formula of the periodic breaking span of thick and hard roof. The two formulas are used to verify the breaking span of thick and hard roof of Tashan Coal Mine, proving that its accuracy is higher than that of traditional beam theory. This paper studies the distribution characteristics of strain energy density in front of the coal seam during the mining process by numerical simulation, which is compared with the results of field microseismic experiments. It is found that the strain energy density of the coal seam has a good correlation with the probability of microseismic events. This paper provides theoretical support for more precise calculation of breaking span of the thick and hard roof and technical support for the practical stability analysis of the surrounding rock under the thick and hard roof.
\end{abstract}

\section{Introduction}

The characteristics of thick and hard roof are large thickness, high strength, poor joint fissure development, strong integrity, and strong self-bearing ability [1]. In the coal face with thick and hard roof, the roof is not easy to collapse after coal mining, which can easily cause the roof to form a large area of the suspension. Thus, this kind of roof will gather a lot of strain energy in the coal seam and surrounding rock. When the thick and hard roof breaks, it can release huge energy and produce strong dynamic load effect, which can easily lead to support destruction, working face collapse, rock burst, and other events $[2,3]$; the problem exists in many mining areas in China such as Datong, Zaozhuang, Tonghua, Hegang, and Qitaihe; Russia and Western Europe countries also have similar problems. So it is the key to ensure the safe production of mine by accurately grasping the breaking span of thick and hard roof and the distribution of strain energy in coal seam. However, the previous studies could not obtain the accurate breaking span of the hard and thick roof and did not know enough the distribution of strain energy in the coal seam under thick and hard roof. Hence the management for the mine dynamic disaster under the action of thick and hard roof was in a relative passive position.

Usually, the beam theory is used to calculate the breaking span of roof, using the mechanical mode of fixed beam with line loaded to get the first and periodic breaking span, and the stress distribution in rock beam is analyzed by using the material mechanics theory [4]. Qian et al. [5] simplified the roof as a fixed beam and a simply supported beam to calculate the first and periodic breaking span of the roof. This method has shown high precision to analyze the shallow beam. However, this calculation can lead to a big error when the roof thickness is so large that it cannot be ignored compared with 
roof span. In addition, the beam theory can not describe the space motion of roof. So researchers have begun to focus on the plate theory, in which the thin plate theory is widely used. Based on the thin plate theory, researchers have done a lot of work: Zhang and Cao [6] studied the first caving fracture mechanism of overlying roof rock in steep thick coal seam; Tu et al. [7] studied the deformation and fracture feature of steep inclined coal seam roof; Wang et al. [8] studied the fracture mode and evolution of main roof stratum above longwall fully mechanized top-coal caving in steeply inclined thick coal seam. Although the thin plate theory can describe the roof space motion, it can only be applied to the thin roof but not the thick one. So it is the key to choose a suitable thick plate theory to study the breaking span of thick roof.

The thick and hard roof breaking has an important effect on the stability of surrounding rocks and coal seam [9, 10]. For the stability of coal seam, the previous researches mainly focused on the change of vertical stress of the front coal seam after excavation and judged whether the front coal seam was in a stable state. Researchers like Wang et al. [11] researched the pressure-relief mechanism of lower seam extraction after upper seam extraction according to the abutment stress in coal seam; Chang et al. [12] analyzed the rib spalling mechanism of fully mechanized top-coal caving face with great mining height in extra-thick coal seam according to the abutment pressure. Meanwhile, coal seam is in the multidirectional stress state. And energy is the result of the combined action of multidirectional stress, which also has a very important influence on the stability of the coal seam and the surrounding rock. The mining practice proves that analyzing the elastic strain energy in the coal seam is the basis for controlling the rock burst, coal, and gas outburst. Aggregation and release of strain energy in coal are also an important cause of the catastrophic failure in the underground chamber. Therefore, studying the strain energy distribution in coal seam is significant [13-15]. At present, it is difficult to study the strain energy distribution characteristics of coal seam in theory completely, and it is necessary to combine theory and numerical simulation for the study.

Given the above, according to the mechanical model suitable for thick and hard roof, this paper is intended to get the theoretical formula of the first breaking span of thick and hard roof by using Reissner plate theory and combining with weighted residual method, with four edges clamped as the boundary conditions and get the theoretical formula of the periodic breaking span of thick and hard roof by using the the modified Vlasov plate theory, with four edges simply supported as the boundary conditions. Furthermore, this paper is intended to study the distribution law of strain energy of coal seam under the action of thick and hard roof through the 3DEC numerical simulation software and the corresponding theoretical formula. At last, taking one of the most representative thick and hard roof in the world, Tashan Coal Mine roof, as example, the breaking span formulas are going to be verified, and the correlation between the strain energy of coal seam and field measured microseismic activity is also going to be discussed as well. So the purpose of this paper is to provide theoretical support for more precise calculation of breaking span of the thick and hard roof and provide technical support for the practical stability analysis of the surrounding rock through the distribution law of the strain energy in the coal seam.

\section{Theoretical Derivation of Breaking Span of Thick and Hard Roof}

2.1. Mechanics Model. The classification criteria for the plate is as follows [16]: usually the thin plate meets the following conditions:

$$
\left(\frac{1}{80} \sim \frac{1}{100}\right) \leq \frac{h}{a} \leq\left(\frac{1}{5} \sim \frac{1}{8}\right),
$$

where $a$ is the smaller side length of the plate, that is, the roof breaking span; $h$ is the thickness of the plate. Otherwise, the plate is thick plate which meets conditions

$$
\frac{h}{a}>\left(\frac{1}{5} \sim \frac{1}{8}\right)
$$

or film which meets the following conditions:

$$
\frac{h}{a}<\left(\frac{1}{80} \sim \frac{1}{100}\right) .
$$

In the study, the ratio of thickness and span of thick and hard roof is between $1 / 5$ and $1 / 8$; therefore, thick plate theory should be used to calculate the breaking span of roof.

The stope roof is simplified to a rectangular plate. With the excavation of the coal seam, the boundary condition of rectangular roof is also changing. At the beginning during the coal seam mining, no cracks in the boundary of roof rock mass appear, where boundary condition is four-edge fixed. As the excavation continues, the size of the goaf roof increases, and the midpoint of the long side of the roof will firstly enter the plastic state and then extend to form a plastic hinge along the long side. And then, the midpoint of the short side of the roof plate will also enter the plastic state and form a plastic hinge along the short side, where boundary condition is four-edge simply supported. When the boundary condition changes from four-edge fixed to four-edge simply supported, which means weakening the boundary constraint, the roof still remains whole without breaking at this time. As the coal mining face continues to advance, a plastic hinge along the $x$-axis appears in the central position of the roof and then extends to both sides to form an internal plastic strand. The plastic strand further expands and divides into 4 plastic strands extending to the apex of the rectangular plate, resulting in the " $\mathrm{X}$ " type breaking. The breaking process is shown in Figure 1.

Due to the different boundary conditions, it is necessary to derive the theoretical formulas of the first breaking span and the periodic breaking span of the thick and hard roof, respectively. Reissner theory is a relatively mature thick plate theory when the boundary condition is four-edge fixed, while Vlasov theory is a relatively simple plate theory with high precision when the boundary condition is four-edge simply supported. Therefore, Reissner thick plate theory and Vlasov plate theory are used to derive the first breaking span and the theoretical breaking span, respectively. 
2.2. Theoretical Derivation of First Breaking Span of Thick and Hard Roof. Reissner made a straight line hypothesis instead of straight normal, that is, the line which is perpendicular to the middle surface before deformation is still a line after deformation. Considering the effect of shear strain $\gamma_{x z}$, $\gamma_{y z}$ and using the variational principle of generalized complementary energy, Reissner derived the partial differential equations of sixth order of elastic surface. Reissner thick plate theory is both a breakthrough to the thin plate theory and a widely used thick plate theory. The basic equations of the static problem based on the Reissner plate theory are as follows [17]:

$$
D \nabla^{4} w=q(x, y)-\frac{h^{2}(2-\mu)}{10(1-\mu)} \nabla^{2} q(x, y),
$$

where $D$ is the bending stiffness of the plate, $D=E h^{3} / 12(1-$ $\left.\mu^{2}\right) ; \nabla^{4}$ is the biharmonic operator, and its expression is $\nabla^{4}=$ $\partial^{4} / \partial x^{4}+2\left(\partial^{4} / \partial x^{2} \partial y^{2}\right)+\partial^{4} / \partial y^{4} ; E$ is the elastic modulus; $w$ is the deflection surface of thick plate; $\mu$ is the Poisson ratio; $q(x, y)$ is the load acting on the plate. The expression of the internal force, bending moment, and rotation in the Reissner plate theory are as follows:

$$
\begin{aligned}
& Q_{x}=-D \frac{\partial}{\partial x} \nabla^{2} w-\frac{h^{2}(2-\mu)}{10(1-\mu)} \frac{\partial q}{\partial x}+\frac{\partial \varphi}{\partial y}, \\
& Q_{y}=-D \frac{\partial}{\partial y} \nabla^{2} w-\frac{h^{2}(2-\mu)}{10(1-\mu)} \frac{\partial q}{\partial y}+\frac{\partial \varphi}{\partial x}, \\
& M_{x}=-D\left|\frac{\partial^{2} w}{\partial x^{2}}+\mu \frac{\partial^{2} w}{\partial y^{2}}\right|-\frac{h^{2}}{5} D \frac{\partial^{2}}{\partial x^{2}} \nabla^{2} w \\
& -\frac{h^{4}(2-\mu)}{50(1-\mu)} \frac{\partial^{2} q}{\partial x^{2}}+\frac{h^{2}}{5} \frac{\partial \varphi}{\partial x \partial y}-\frac{h^{2} \mu}{10(1-\mu)} q, \\
& M_{y}=-D\left|\frac{\partial^{2} w}{\partial y^{2}}+\mu \frac{\partial^{2} w}{\partial x^{2}}\right|-\frac{h^{2}}{5} D \frac{\partial^{2}}{\partial y^{2}} \nabla^{2} w \\
& -\frac{h^{4}(2-\mu)}{50(1-\mu)} \frac{\partial^{2} q}{\partial y^{2}}+\frac{h^{2}}{5} \frac{\partial \varphi}{\partial x \partial y}-\frac{h^{2} \mu}{10(1-\mu)} q, \\
& w_{x}=-\frac{\partial w}{\partial x}-\frac{h^{2}}{5(1-\mu)} \frac{\partial}{\partial x} \nabla^{2} w-\frac{h^{4}(2-\mu)}{50(1-\mu)} \frac{\partial q}{\partial x} \\
& +\frac{h^{2}}{5(1-\mu) D} \frac{\partial \varphi}{\partial y} \\
& w_{y}=-\frac{\partial w}{\partial y}-\frac{h^{2}}{5(1-\mu)} \frac{\partial}{\partial y} \nabla^{2} w-\frac{h^{4}(2-\mu)}{50(1-\mu)} \frac{\partial q}{\partial y} \\
& +\frac{h^{2}}{5(1-\mu) D} \frac{\partial \varphi}{\partial x} \text {. }
\end{aligned}
$$

The short side of the rectangular plate is $a$, representing the advancing distance of working face. The long side of the rectangular plate is $b$, representing the working face width.

And $a$ is an unknown value that we want; $b$ is a known value. Then the boundary conditions are as follows:

$$
\begin{gathered}
w_{x=0, a}=0 ; \\
w_{y=0, b}=0 ; \\
\frac{\partial w}{\partial x_{x=0, a}}=0 ; \\
\frac{\partial w}{\partial y_{y=0, b}}=0 .
\end{gathered}
$$

In order to meet the above boundary conditions, the following trial function is selected:

$$
w=c x^{2}(a-x)^{2} y^{2}(b-y)^{2} .
$$

According to its formulation, the trial function is confirmed if the form of $c$ is determined. Combined with the weighted residual method, the trial function is substituted into the Galerkin form of formula (4) [18]:

$$
\begin{aligned}
& \int_{0}^{a} \int_{0}^{b}\left[D \nabla^{4} w-q(x, y)+\frac{h^{2}(2-\mu)}{10(1-\mu)}\right. \\
& \left.\cdot \nabla^{2} q(x, y)\right] \cdot x^{2}(a-x)^{2} y^{2}(b-y)^{2} \\
& \quad=0 .
\end{aligned}
$$

Expand the load on the thick plate into a double triangular series; that is,

$$
q(x, y)=\sum_{m=1}^{\infty} \sum_{n=1}^{\infty} q_{m n} \sin \frac{m \pi x}{a} \sin \frac{n \pi y}{b} .
$$

With the increase of $m, n, q_{m n}$ decreases sharply, and the increase of $m, n$ has little effect on the deflection of the roof, so $m=n=1$ can ensure the accuracy. Now formula (14) can be simplified as

$$
q(x, y)=q_{11} \sin \frac{\pi x}{a} \sin \frac{\pi y}{b}
$$

where $q_{11}$ is the uniform load on the thick and hard roof. Substituting (15) into (13) and using mathematical software Mathematica to get the expression of $c$ 

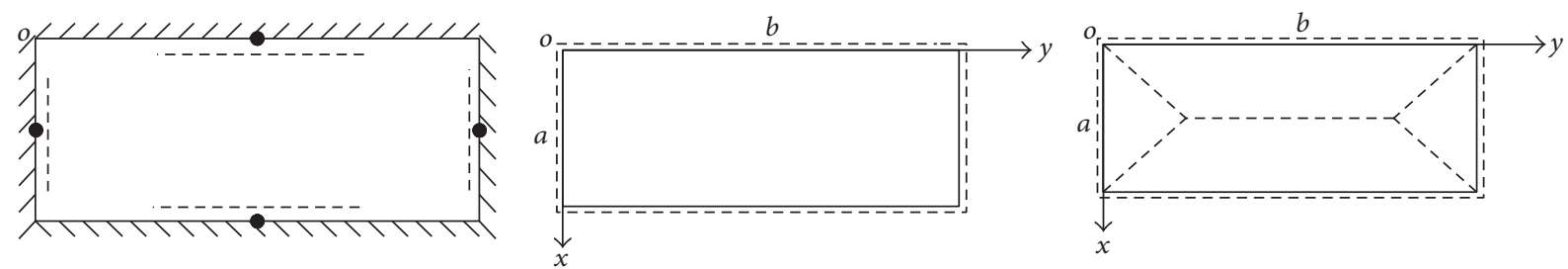

FIGURE 1: Three stages of roof breaking.

$$
c=\frac{8820\left(-12+\pi^{2}\right)^{2} q_{11}\left(a^{2}\left(h^{2} \pi^{2}(-2+\mu)+10 b^{2}(-1+\mu)\right)+b^{2} h^{2} \pi^{2}(-2+\mu)\right)}{a^{2} b^{2}\left(7 a^{4}+4 a^{2} b^{2}+7 b^{4}\right) D \pi^{10}(-1+\mu)} .
$$

We can get the deflection function of the roof when substituting (16) into (12):

$$
w=\frac{8820\left(-12+\pi^{2}\right)^{2} q_{11}\left(a^{2}\left(h^{2} \pi^{2}(-2+\mu)+10 b^{2}(-1+\mu)\right)+b^{2} h^{2} \pi^{2}(-2+\mu)\right)}{a^{2} b^{2}\left(7 a^{4}+4 a^{2} b^{2}+7 b^{4}\right) D \pi^{10}(-1+\mu)} x^{2}(a-x)^{2} y^{2}(b-y)^{2}
$$

The bending moments $M_{x}, M_{y}$ of thick plate which is four-edge fixed can be obtained when substituting (17) into (7) and (8). And $M_{x}, M_{y}$ both get the maximum value when $x=a / 2, y=b / 2$. The maximum bending moment of the thick plate can be expressed as $M_{\max }=\max \left(M_{x \max }, M_{y \max }\right)$. Finally, the expression of the maximum bending moment $M_{\max }$ is obtained in Mathematica:

$$
\begin{aligned}
& M_{\max } \\
& =-\frac{1}{5}\left(\frac{1.72321 \times 10^{6}\left(879.637+a^{2}\right)(-460+b)^{2} b^{2}}{a^{2}\left(2.8 \times 10^{9}+30228.6 a^{2}+a^{4}\right) D}\right. \\
& \left.-\frac{3.45 \times 10^{6}\left(879.637+a^{2}\right)\left(35266.7-460 b+b^{2}\right)}{\left(2.8 \times 10^{9}+30228.6 a^{2}+a^{4}\right) D}\right) \\
& \cdot D h^{2}+\frac{h^{4} \pi^{2} q_{11}(-2+\mu)}{50 a^{2}(-1+\mu)}+\frac{h^{2} q_{11} \mu}{10(-1+\mu)} \\
& -D\left(-\frac{71800.3\left(879.637+a^{2}\right)(-460+b)^{2} b^{2}}{\left(2.8 \times 10^{9}+30228.6 a^{2}+a^{4}\right) D}\right. \\
& +\frac{215401 a^{2}\left(879.637+a^{2}\right)\left(35266.7-460 b+b^{2}\right)}{\left(2.8 \times 10^{9}+30228.6 a^{2}+a^{4}\right) D} \\
& \cdot \mu) .
\end{aligned}
$$

The relationship between the tensile strength $\sigma_{\max }$ and the maximum bending moment $M_{\max }$ is as follows:

$$
\sigma_{\max }=\frac{12 M_{\max }}{h^{3}} z=\frac{12 M_{\max }}{h^{3}} \cdot \frac{h}{2}=\frac{6 M_{\max }}{h^{2}} .
$$

The thick plate breaking discriminant under four-edge fixed condition can be obtained when substituting (18) into (19).

$\sigma_{\max }$ is the tensile strength of the roof. Now we can get the value of $a$, the first breaking span of thick and hard roof, by substituting the parameter values involved in (19).

\subsection{Theoretical Derivation of Periodic Breaking Span of Thick} and Hard Roof. After the first breaking of the roof, as the coal face continues to move forward, periodic breaking will occur. The breaking of thick and hard roof often results in a large dynamic load, leading to cracks in the boundary of the front unbroken roof, which helps the boundary enter into the plastic state quickly. Meanwhile, it is easy to form a hinge relationship between the unbroken roof and broken roof. Therefore, the boundary condition of the roof can be simplified as four-edge simply supported condition.

Under this boundary condition, the Vlasov plate theory which considers horizontal shear deformation has the advantages of high precision and simple form [19]. Therefore, this paper will use the Vlasov plate theory to derive the periodic breaking span of thick and hard roof.

Considering the horizontal shear deformation, it is assumed that the true displacement of each point on the middle surface normal is nonlinear, and the relationship between the shear stress and the displacement is as follows:

$$
\begin{gathered}
\tau_{x z}=\frac{E}{2(1+\mu)}\left(\frac{\partial u}{\partial z}+\frac{\partial \omega}{\partial x}\right), \\
\tau_{y z}=\frac{E}{2(1+\mu)}\left(\frac{\partial v}{\partial z}+\frac{\partial \omega}{\partial y}\right) .
\end{gathered}
$$


The rotation angle of straight normal on the middle surface can be obtained from formula (20):

$$
\begin{gathered}
\varphi_{x}=\frac{\partial \omega}{\partial x}-\frac{\tau_{x z}^{0}}{G}, \\
\varphi_{y}=\frac{\partial \omega}{\partial y}-\frac{\tau_{y z}^{0}}{G} .
\end{gathered}
$$

For rectangular plate with four-edge simply supported condition, the boundary conditions are as follows:

$$
\begin{gathered}
w_{x=0, a}=0, \\
w_{y=0, b}=0, \\
\frac{\partial^{2} w}{\partial x_{x=0, a}^{2}}=0, \\
\frac{\partial^{2} w}{\partial y_{y=0, b}^{2}}=0 .
\end{gathered}
$$

Based on formula (21), the forces and moments of thick plate can be deduced:

$$
\begin{aligned}
& M_{x}=-\frac{D}{5}\left[4\left(\frac{\partial \varphi_{x}}{\partial x}+\mu \frac{\partial \varphi_{y}}{\partial y}\right)+\left(\frac{\partial^{2} \omega}{\partial x^{2}}+\mu \frac{\partial^{2} \omega}{\partial y^{2}}\right)\right], \\
& M_{y}=-\frac{D}{5}\left[4\left(\frac{\partial \varphi_{y}}{\partial y}+\mu \frac{\partial \varphi_{x}}{\partial x}\right)+\left(\frac{\partial^{2} \omega}{\partial y^{2}}+\mu \frac{\partial^{2} \omega}{\partial x^{2}}\right)\right] .
\end{aligned}
$$

And the differential equations of plate bending are rewritten as follows:

$$
\begin{aligned}
& \frac{2 D}{5}\left[(1-\mu) \nabla^{2} \varphi_{x}+(1+\mu) \frac{\partial \phi}{\partial x}+\frac{1}{2} \frac{\partial}{\partial x}\left(\nabla^{2} \omega\right)\right] \\
& +\frac{2}{3} G h\left(\frac{\partial \omega}{\partial x}-\varphi_{x}\right)=0, \\
& \frac{2 D}{5}\left[(1-\mu) \nabla^{2} \varphi_{y}+(1+\mu) \frac{\partial \phi}{\partial y}+\frac{1}{2} \frac{\partial}{\partial y}\left(\nabla^{2} \omega\right)\right] \\
& +\frac{2}{3} G h\left(\frac{\partial \omega}{\partial y}-\varphi_{y}\right)=0 .
\end{aligned}
$$

The deflection and rotation angle displacement functions are transformed into the following double trigonometric series:

$$
\begin{aligned}
\omega & =\sum_{m=1}^{\infty} \sum_{n=1}^{\infty} A_{m n} \sin \frac{m \pi x}{a} \sin \frac{n \pi y}{b}, \\
\varphi_{x} & =\sum_{m=1}^{\infty} \sum_{n=1}^{\infty} B_{m n} \cos \frac{m \pi x}{a} \sin \frac{n \pi y}{b}, \\
\varphi_{y} & =\sum_{m=1}^{\infty} \sum_{n=1}^{\infty} C_{m n} \sin \frac{m \pi x}{a} \cos \frac{n \pi y}{b} .
\end{aligned}
$$

At this time, all the board boundary conditions have been met. Furtherly, the horizontal load $q(x, y)$ can also be transformed into the following double trigonometric series:

$$
q(x, y)=\sum_{m=1}^{\infty} \sum_{n=1}^{\infty} q_{m n} \sin \frac{m \pi x}{a} \sin \frac{n \pi y}{b} .
$$

Substituting (25) and (26) into (23), we can get the expressions of $A_{m n}, B_{m n}, C_{m n}$ :

$$
\begin{aligned}
A_{m n}= & \left\{1+\frac{6 D \pi^{2}}{5 G h}\left[\left(\frac{m}{a}\right)^{2}+\left(\frac{n}{b}\right)^{2}\right]\right\} \\
& \times \frac{q_{m n}}{D \pi^{4}\left[(m / a)^{2}+(n / b)^{2}\right]^{2}}, \\
B_{m n}= & \left\{1-\frac{3 D \pi^{2}}{10 G h}\left[\left(\frac{m}{a}\right)^{2}+\left(\frac{n}{b}\right)^{2}\right]\right\} \\
& \times \frac{m q_{m n}}{a D \pi^{3}\left[(m / a)^{2}+(n / b)^{2}\right]^{2}} \\
C_{m n}= & \left\{1-\frac{3 D \pi^{2}}{10 G h}\left[\left(\frac{m}{a}\right)^{2}+\left(\frac{n}{b}\right)^{2}\right]\right\} \\
& \times \frac{n q_{m n}}{a D \pi^{3}\left[(m / a)^{2}+(n / b)^{2}\right]^{2}} .
\end{aligned}
$$

As with the roof first breaking, the load on the roof is uniform load too. With the increase of $m, n, q_{m n}$ decreases sharply, and the increase of $m, n$ has little effect on the deflection of the roof, so $m=n=1$ can ensure the accuracy. The values of $A_{m n}, B_{m n}, C_{m n}$ can be obtained when substituting $m=n=1$ into formula (27) and then the values of $\omega, \varphi_{x}, \varphi_{y}$ can be obtained when substituting these three values into formula (25); furtherly, the values of $M_{x}$, $M_{y}$ can be obtained when substituting the values of $\omega, \varphi_{x}$, $\varphi_{y}$ into formula (23). And when $x=a / 2, y=b / 2, M_{x}$, $M_{y}$ both get the maximum value. In addition, according to the relationship between the tensile strength $\sigma_{\max }$ and the maximum bending moment $M_{\max }$,

$$
M_{\max }=\frac{\sigma_{\max } \times h^{2}}{6},
$$

we can get the discriminant of thick plate breaking with fouredge simply supported condition:

$$
\begin{aligned}
\sigma_{\max }= & \frac{6 M_{\max }}{h^{2}} \\
= & \frac{6 q\left(5 / a^{2}+4 \mu / a b+\mu / b^{2}\right)}{5 \pi^{2}\left(1 / a^{2}+1 / b^{2}\right)^{2} h^{2}} \\
& +\frac{6 q \mu\left(1 / b^{2}-1 / a b\right)}{25(1-\mu)\left(1 / a^{2}+1 / b^{2}\right)},
\end{aligned}
$$

where $E$ is the elastic modulus; $\mu$ is the Poisson ratio; $v, u$ are plane displacements; $w$ is the deflection surface of thick plate; 


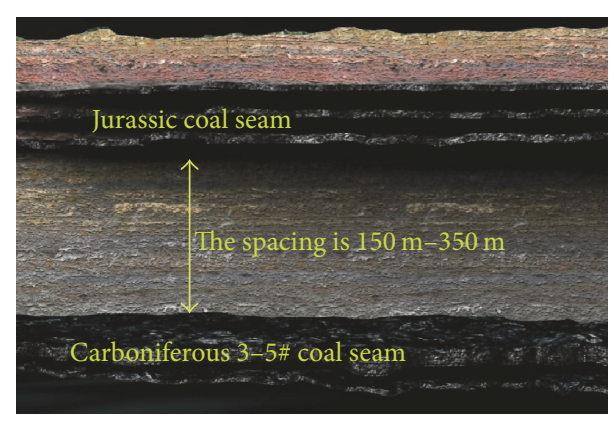

Figure 2: The distribution of the double coal seam diagram in Datong mining area.

$\tau_{x z}^{0}, \tau_{y z}^{0}$ are the transverse shear stresses of middle surface; $D$ is the bending stiffness of the plate, $D=E h^{3} / 12\left(1-\mu^{2}\right) ; G$ is the shear modulus, $G=E / 2(1+\mu)$; $h$ is the plate thickness; and $\nabla^{2}$ is the Laplacian operator.

The value of $a$, the periodic breaking span of thick and hard roof, can be obtained when substituting the parameter values involved in (29).

2.4. In Field Validation. In order to verify the accuracy of the derived formulas when calculating the first and the periodic breaking span of thick and hard roof and also compared with the accuracy of traditional beam theory, the 20-meter-thick hard lamprophyre of 8212 working face of Tashan Coal Mine in Datong, China, is selected as the calculation object. Datong mining area is dual system coal seam; as the upper Jurassic resource exhausted, the main coal seam is shifting to the lower Carboniferous coal seam. The distance between the double coal seams is $150 \sim 350 \mathrm{~m}$. The depth of Carboniferous coal seam is $400 \sim 600 \mathrm{~m}$. In Carboniferous coal seam, it is 3-5\#. The distribution of the double coal seam diagram in Datong mining area is shown in Figure 2.

The working face is mining 3-5\# coal seam, with the average buried depth 474 meters, dip angle $3^{\circ}$ which is flat seam. The average thickness of $3-5 \#$ coal seam is 12 meters, which is typical extremely thick coal seam in China. Conventional longwall top-coal caving (CLTCC) is the mining method used in Tashan Coal Mine [20]. The advancing length and the width of the coal face are $2800 \mathrm{~m}$ and $230 \mathrm{~m}$, respectively. The cutting height of coal is $3.5 \mathrm{~m}$ and the top-coal caving height is $8.5 \mathrm{~m}$. The advance speed of work face is $5 \mathrm{~m} / \mathrm{d}$. The tensile strength of the roof studied in this paper reaches $12 \mathrm{MPa}$, and the thickness of the roof is $20 \mathrm{~m}$. The histogram of 8212 fully mechanized caving faces is shown in Figure 3, the red font label part represents the excavation coal seam, and the blue font label part represents the thick and hard roof studied in the paper.

In field measurement, before forced caving measures such as hydraulic fracturing and presplitting blasting, the first breaking span of the 20-meter-thick lamprophyre can reach about $110 \mathrm{~m}$, and the periodic breaking span of the 20-meter-thick lamprophyre can reach between $65 \mathrm{~m}$ and $75 \mathrm{~m}$. So, the two ratios, one being thickness and the first breaking span of roof and the other being thickness and
TABLE 1: The value of parameters involved in calculation.

\begin{tabular}{lc}
\hline Parameters involved in calculation & Value \\
\hline$\mu$ & 0.21 \\
$h$ & $20 \mathrm{~m}$ \\
$\sigma_{\max }$ & $12 \mathrm{MPa}$ \\
$b$ & $230 \mathrm{~m}$ \\
$q_{1}$ & $1.85 \mathrm{MPa}$ \\
\hline
\end{tabular}

the periodic breaking span of roof, are all between 1/5 and $1 / 8$, which is applicable to the thick plate theory. Every time the thick and hard roof breaks, the pressure of the working face increases obviously, and it lasts a long time. The safety valves of hydraulic supports open frequently and the maximum descent speed of the support column is $320 \mathrm{~mm} / \mathrm{h}$. The resistance of the hydraulic support can reach $14000 \mathrm{kN}$, which can easily cause the breakage of the support. At this time, the collapse phenomenon is serious, and the pressure in the middle of the working face is extremely obvious. Figure 4 shows the strong pressure behavior when the 20-meter-thick roof is breaking.

The mechanical parameters of thick and hard roof are $\mu=$ $0.21, h=20 \mathrm{~m}, \sigma_{\max }=12 \mathrm{MPa}, b=230 \mathrm{~m}$.

In addition to the dead weight, the effective load of any rock stratum in the overlying strata is usually subjected to the interaction of the overlying adjacent rock layers. Generally speaking, the load of stratum is not uniformly distributed, but in order to analyze the problem conveniently, it is assumed that rock load is uniformly distributed [5]. The calculation of rock effective load is shown in Figure 5.

Suppose that the first layer is a key stratum, the number of upper strata is $m$, and the number of strata controlled by key strata is $n$. The strata from the first layer to the $n$ layer deform synchronously and form a composite body, and the load of the first layer is

$$
q=\frac{E_{1} h_{1}^{3} \sum_{i=1}^{n} \gamma_{i} h_{i}}{\sum_{i=1}^{n} E_{i} h_{i}^{3}}
$$

where $E_{i}$ is the elastic modulus of layer $i, h_{i}$ is the thickness of layer $i, \gamma_{i}$ is the bulk density of layer $i$, and $n$ is the number of strata controlled by the key layer.

The key strata theory shows that $[21,22]$ both the 4-meterthick hard lower lamprophyre and the 20-meter-thick hard upper lamprophyre are inferior key strata. From the top of the histogram to the surface that is not drawn in the histogram, there is tens of meters-thick sandstone, that is, the main key stratum, with high integrity and nonobvious stratification.

According to the strata histogram and the key strata theory, the upper lamprophyre controlled height is $54.1 \mathrm{~m}$, getting to the sandy mudstone layer, while the lower lamprophyre controlled height is $4 \mathrm{~m}$, that is, the thickness of 2\# coal seam. Uniform load on the upper lamprophyre can be obtained through formula (30); that is, $q_{1}=1.85 \mathrm{MPa}$.

At this stage, all the parameter values of the first and the periodic breaking span of the thick and hard roof have been determined, as shown in Table 1. 


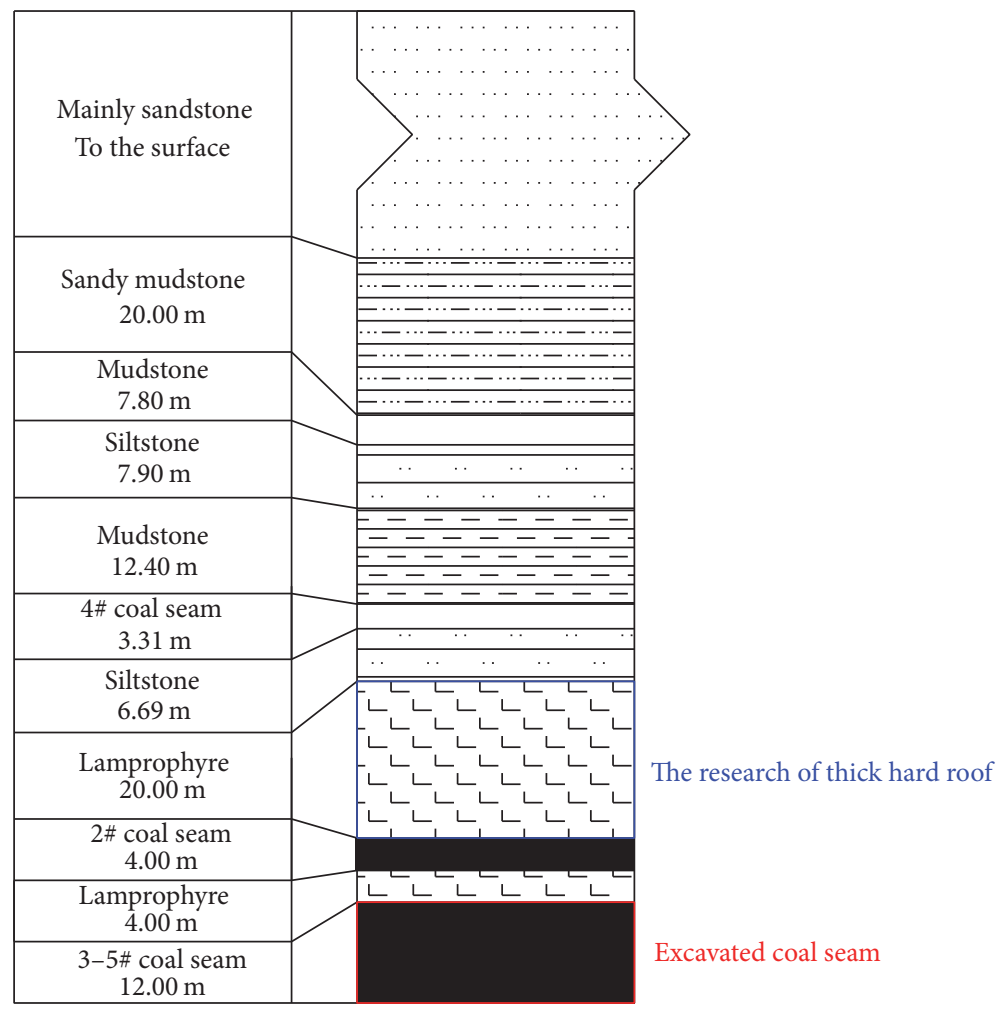

FIGURE 3: The histogram of 8212 fully mechanized caving face.
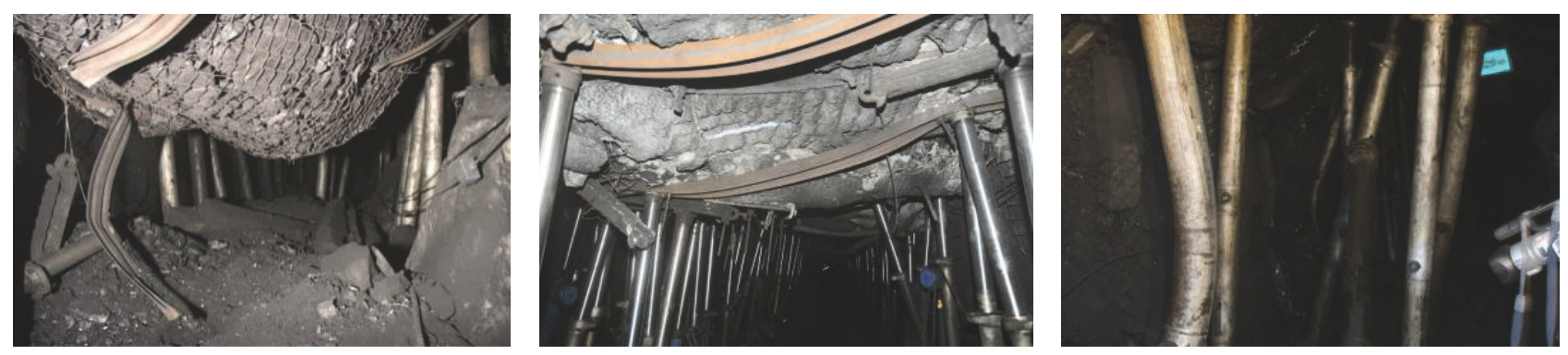

FIGURE 4: The strong pressure behavior when $20 \mathrm{~m}$ thick roof is broken.

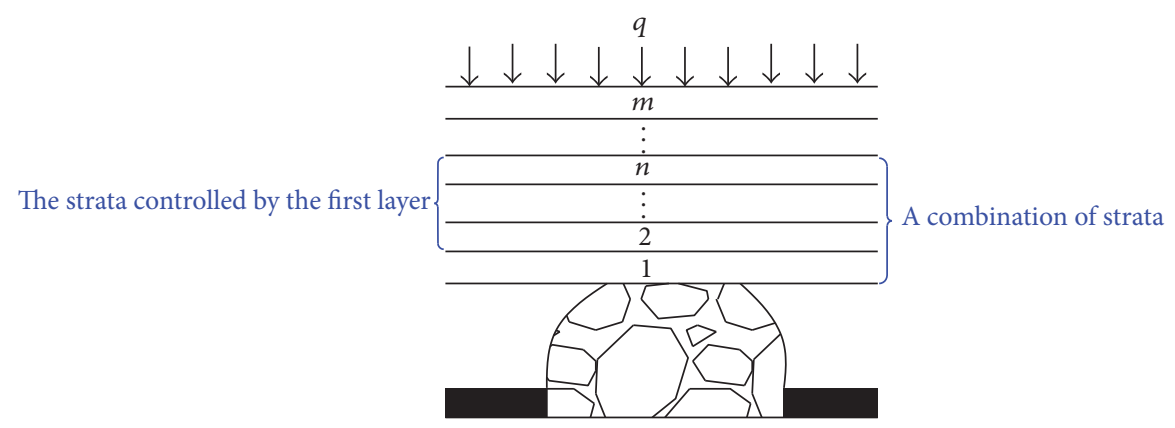

FIGURE 5: The effective load calculation diagram of stratum. 
Through formula (19) and formula (29), we can calculate that the values of the first and the periodic breaking span of the thick and hard roof are $120.654 \mathrm{~m}$ and $69.4 \mathrm{~m}$, respectively.

When using the beam theory to calculate the first breaking span of the roof, the formula is

$$
l_{c}=h \sqrt{\frac{2 \sigma_{\max }}{q}} .
$$

When using the beam theory to calculate the periodic breaking span of the roof, the formula is

$$
l_{s}=2 h \sqrt{\frac{\sigma_{\max }}{(3 q)}} .
$$

Through formula (31) and formula (32), we can calculate the values of the first and the periodic breaking span of the thick and hard roof of 8212 working faces are $72.036 \mathrm{~m}$ and $58.817 \mathrm{~m}$, respectively.

The error rate $e$ is defined as

$$
e=\frac{\left|Q_{C}-Q_{A}\right|}{Q_{A}} \times 100 \%,
$$

where $Q_{C}$ is the value of formula calculation and $Q_{A}$ is the value of field measurement.

According to formula (33) to calculate the error rate, we can compare the two methods in order to know which one is more scientific. According to the beam theory, the error rate of the first breaking span and the biggest error rate of the periodic breaking span of thick and hard roof of 8212 working faces are $34.5 \%$ and $21.6 \%$, respectively; the former rate is obtained from formula (31) and the latter from formula (32), while, in this paper, the two error rates, $9.69 \%$ and $7.47 \%$, are obtained from the derived formula (19) based on the Reissner plate theory and the derived formula (29) based on the Vlasov plate theory, respectively.

In order to verify the correctness of the deduced theoretical formula again, the 8206 working face of Tashan Coal Mine is selected as the calculation object too. The histogram of 8206 working faces is basically the same as that of the 8212 working faces; there is only a slight difference in rock thickness; the mechanical parameters of the corresponding rock strata are consistent. Because of the limited space, the histogram of 8206 working faces is no longer given here. The width of the working face is $205 \mathrm{~m}$, the advance speed of the working face is $5.6 \mathrm{~m} / \mathrm{d}$, and the thickness of the roof is $21 \mathrm{~m}$; according to the previous calculation method, the uniform load on the upper lamprophyre can be obtained through formula (30); that is, $q_{1}=1.92 \mathrm{MPa}$. In field measurement, the first breaking span can reach about $118 \mathrm{~m}$, and the periodic breaking span of can reach between $68 \mathrm{~m}$ and $77 \mathrm{~m}$. Through formula (19) and formula (29), we can get the values of the first and the periodic breaking span of the thick and hard roof which are $130.039 \mathrm{~m}$ and $73.735 \mathrm{~m}$, respectively, and the two error rates are $10.2 \%$ and $8.43 \%$, respectively; through formula (31) and formula (32), we can get the values which are $74.246 \mathrm{~m}$ and $60.622 \mathrm{~m}$, respectively; the two error rates are $38.77 \%$ and $21.3 \%$, respectively.
In conclusion, the accuracy of derived calculation formulas based on the thick plate theory in this paper is higher than the beam theory to get the breaking span of the thick and hard roof.

\section{Strain Energy Distribution Characteristics of Coal Seam under Thick and Hard Roof}

Because of good stability and large breaking span, the thick and hard roof can accumulate a large amount of strain energy in the coal seam. Once the thick and hard roof collapses, it will cause huge energy release, forming strong pressure. The energy release is sudden, transient, and destructive, as shown in Figure 4. Therefore, it is necessary to study the distribution characteristics of the strain energy in the coal seam under thick and hard roof action. According to the generalized Hooke's law, the stress and strain meet the following relationship under the condition of spatial stress:

$$
\begin{aligned}
& \varepsilon_{1}=\frac{\left[\sigma_{1}-u\left(\sigma_{2}+\sigma_{3}\right)\right]}{E}, \\
& \varepsilon_{2}=\frac{\left[\sigma_{2}-u\left(\sigma_{1}+\sigma_{3}\right)\right]}{E}, \\
& \varepsilon_{3}=\frac{\left[\sigma_{3}-u\left(\sigma_{1}+\sigma_{2}\right)\right]}{E},
\end{aligned}
$$

where $\sigma_{1}, \sigma_{2}, \sigma_{3}$ are principal stress and $\varepsilon_{1}, \varepsilon_{2}, \varepsilon_{3}$ are principal strain. Under the condition of spatial stress, the formula of strain energy density is as follows:

$$
v_{\varepsilon}=\frac{1}{2}\left(\sigma_{1} \varepsilon_{1}+\sigma_{2} \varepsilon_{2}+\sigma_{3} \varepsilon_{3}\right)
$$

Substituting (34) into (35), we can get

$$
\begin{aligned}
& v_{\varepsilon} \\
& =\frac{1}{2 E}\left[{\sigma_{1}}^{2}+{\sigma_{2}}^{2}+{\sigma_{3}}^{2}-2 u\left(\sigma_{1} \sigma_{2}+\sigma_{1} \sigma_{3}+\sigma_{2} \sigma_{3}\right)\right] .
\end{aligned}
$$

Therefore, in order to know the distribution of strain energy density of coal seam under thick and hard roof deformation and failure, it is necessary to know the three principal stress values of the coal seam. Although it is difficult to obtain the three principal components of stress of each point over time, approximate values are obtained through numerical simulation methods. Specifically, we apply here the large scale three-dimensional discrete element software 3DEC. This software can help to study the evolution law of roof strata migration and the stress of the coal seam during the working face advancing [23]. As previous studies have shown that microseismic events are closely related to the energy distribution in coal and rocks [24, 25], this paper tries further exploring the relationship between them, and this section will use 3DEC numerical simulation software to study strain energy distribution characteristics of coal seam under the thick and hard roof deformation and failure in Tashan mine and, then, compare it with the results of field microseismic test. By doing so, this paper may provide a research 
TABLE 2: Mechanic parameters of coal seam and strata.

\begin{tabular}{|c|c|c|c|c|c|}
\hline Strata & Density $/\left(\mathrm{kg} / \mathrm{m}^{3}\right)$ & Bulk modulus/GPa & Shear modulus/GPa & Internal friction angle $/^{\circ}$ & Cohesion/MPa \\
\hline Sandstone & 2810 & 60 & 54.6 & 42 & 1.97 \\
\hline Sandy mudstone & 2678 & 36.3 & 31.2 & 38 & 1.55 \\
\hline Mudstone & 2504 & 2.5 & 1.21 & 31 & 1.38 \\
\hline Siltstone & 2740 & 45.4 & 39.2 & 42 & 1.98 \\
\hline Mudstone & 2500 & 2.78 & 1.2 & 30 & 1.378 \\
\hline 4\# coal seam & 1456 & 2.71 & 1.2 & 31 & 1.349 \\
\hline Siltstone & 2736 & 44.4 & 41.2 & 45 & 1.88 \\
\hline Lamprophyre & 2825 & 46.1 & 42.8 & 49 & 4.87 \\
\hline 2\# coal seam & 1452 & 2.7 & 1.19 & 30 & 1.347 \\
\hline Lamprophyre & 2812 & 44.1 & 41.6 & 47 & 4.63 \\
\hline $3-5 \#$ coal seam & 1450 & 2.68 & 1.18 & 30 & 1.346 \\
\hline Sandstone & 2800 & 58 & 54.4 & 41 & 1.92 \\
\hline
\end{tabular}

way for studying the energy distribution characteristics of the surrounding rock under similar conditions.

Similarly, the thick and hard roof of 8212 working face of Tashan Coal Mine is selected as the simulation object. According to the stratigraphic histogram, the design model has height of $200 \mathrm{~m}$. and length of $300 \mathrm{~m}$. and has a length boundary coal pillar of length of $30 \mathrm{~m}$. Because the coal seam is flat seam, it is assumed to be a horizontal coal seam in the numerical model. The model uses brick units to simulate coal seams and surrounding rocks. And it is assumed that the boundary condition does not change during the excavation; that is, the four sides and the bottom of the model are fixed constraint; the upper part of the model is free boundary; at the top of the model, the uniform load applied by the overlying strata is $q=6.713 \mathrm{MPa}$. Large deformation can occur in rock formations. When the model is calculated, the SOLVRATIO value reaches $1 \times e^{-5}$; we think that the convergence is achieved. Supposing that the rock blocks do not vibrate at the equilibrium position, so the self-adaptive damping is adopted in the model. The Mohr-Coulomb criterion is used in the simulation. Every time in the model, the advance distance of $3-5$ \# coal seam is $5 \mathrm{~m}$; the height of each excavation is $12 \mathrm{~m}$. The mechanic parameters of coal seam and strata are shown in Table 2, and the mechanic parameters of interface of coal seam and strata are shown in Table 3.

As the field microseismic experiments were carried out when the working face advancing distance was $30 \mathrm{~m}, 60 \mathrm{~m}$, $90 \mathrm{~m}, 120 \mathrm{~m}$, and $150 \mathrm{~m}$, respectively, therefore, the numerical simulation experiments also focus on the energy distribution characteristics of coal seam in front of the mining coal wall when the working face advancing distance is $30 \mathrm{~m}, 60 \mathrm{~m}$, $90 \mathrm{~m}, 120 \mathrm{~m}$, and $150 \mathrm{~m}$, respectively. In order to obtain the distribution of strain energy density in front of the coal seam during the mining process, the dense principal stress measuring points are arranged in the coal seam, the schematic diagram of the measuring points arrangement is shown in Figure 6, and the principal stress values of the measuring points are recorded in the process of working face advancing.

The numerical model is shown in Figure 7, and the simulation results are shown in Figure 8.
As can be seen from Figure 8, as the face continues to move forward, thick and hard roof has undergone a significant deformation and breaking process. Finally, the principal stress values of the measuring points are substituted into (36) to obtain the strain energy density. The results are shown in Figure 9.

The following conclusions can be obtained from Figure 9:

(1) The distribution of the strain energy density in front of the working face is similar to that of the stress distribution, which shows the obvious decreasing, increasing, and stable areas. The decreasing area is close to the working face, whose stress value is lower than original rock stress, with little strain energy accumulation. As the distance from the coal wall increases, the strain energy density increases sharply. And the strain energy density is at a higher level when the distance from the working face is between $20 \mathrm{~m}$ and $60 \mathrm{~m}$, where the peak values are obtained. A large amount of strain energy is accumulated in the coal seam in the increasing area. When the distance is far from the working face, the coal seam is almost unaffected by the working face mining, and the strain energy accumulated in the coal seam is generally stable.

(2) When the advance distance increases from $30 \mathrm{~m}$ to $90 \mathrm{~m}$, the strain energy density of the front coal seam at the same distance from the working face increases as the advance distance increases; however, when the advance distance increases from $90 \mathrm{~m}$ to $150 \mathrm{~m}$, the strain energy density of the front coal seam at the same distance from the working face decreases firstly and then increases. The reason is that when the advance distance is lower than $120 \mathrm{~m}$, the roof does not break, and energy has always been in the condition of accumulation; when the working face advancing distance is up to $120 \mathrm{~m}$, the roof breaks, leading to the energy accumulated in the coal seam release.

In the field microseismic experiment, the microseismic events of the surrounding rock were recorded when the 
TABLE 3: Mechanic parameters of interface of coal seam and strata.

\begin{tabular}{lcccc}
\hline Strata & Normal stiffness/GPa & Shear stiffness/GPa & Cohesion/MPa & Internal friction angle $^{\circ}$ \\
\hline Sandstone & 4.2 & 2.2 & 0.49 & 15 \\
Sandy mudstone & 2 & 1.1 & 0.26 & 12 \\
Mudstone & 1.52 & 0.83 & 0.2 & 12 \\
Siltstone & 4.2 & 4 & 0.39 & 9 \\
Mudstone & 1.5 & 0.8 & 0.19 & 10 \\
4\# coal seam & 0.33 & 0.12 & 0.14 & 10 \\
Siltstone & 3.9 & 3.9 & 0.37 & 7 \\
Lamprophyre & 4.2 & 4.2 & 0.67 & 17 \\
2\# coal seam & 0.31 & 0.11 & 0.135 & 9 \\
Lamprophyre & 4 & 4 & 0.63 & 15 \\
3-5\# coal seam & 0.3 & 0.1 & 0.11 & 9 \\
Sandstone & 4 & 2 & 0.47 & 14 \\
\hline
\end{tabular}

The distance between the measuring point and the working face

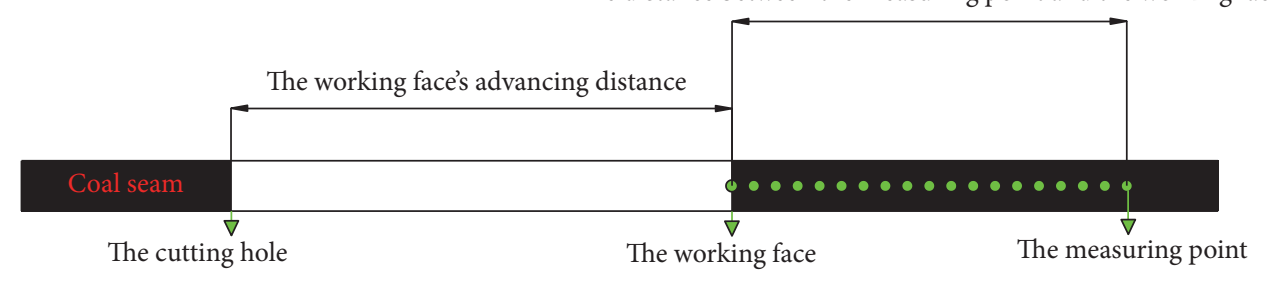

The advancing direction

FIGURE 6: The schematic diagram of the measuring points arrangement.

distance of the face advance was $30 \mathrm{~m}, 60 \mathrm{~m}, 90 \mathrm{~m}, 120 \mathrm{~m}$, and $150 \mathrm{~m}$, respectively. The microseismic system is made up of ground monitoring mainframe, ground photoelectric converter, underground photoelectric converter, underground monitoring mainframe, signal cable, and detector. The microseismic system composition and experimental results are shown in Figures 10 and 11, respectively.

The experiment result shows that microseismic events are few when measuring points are located in $0-20 \mathrm{~m}$ in front of the working face, and microseismic events increase with the increase of the distance from the working face; microseismic events' most intensive area is $20-60 \mathrm{~m}$ ahead of the working face. When the distance from the working face is larger than $60 \mathrm{~m}$, the microseismic events decrease with the increase of the distance. Comparing Figure 11 with Figure 9, it is found that the strain energy accumulated in the coal seam has a good correlation with its microseismic events. That is, when the strain energy of the coal seam is large, the probability of occurrence of microseismic events is greater; when the strain energy of the coal seam is small, the probability of occurrence of microseismic events is lower. The numerical simulation method provides a way to study the distribution of surrounding rock energy in the future.

\section{Discussion}

By making reasonable assumptions on the basis of the plate theory and combining with powerful mathematical software, this paper proves that the accuracy of the derived formula is higher than that of the traditional beam theory when calculating the breaking span of the thick and hard roof. However, some deviations still exist between the calculated results and the field data, and reasons can be summarized as follows. Firstly, the traditional thick plate theory is based on reasonable assumptions, and the paper makes further assumptions on the basis of thick plate theory. Though these assumptions are as much as possible close to the real situation, assumptions can never be completely consistent with the real situation. Secondly, the mechanical parameters involved in the calculation of coal and rock are obtained in the laboratory, which may be a little different from the real ones in the field.

The study of the energy distribution of the coal seam contributes to a better understanding and prevention of the dynamic disasters of the coal and rock mass, especially under the action of thick and hard roof, which can accumulate a lot of energy, easily leading to mine disasters because of the big breaking span of roof. Strain energy has an important position at all kinds of energy in the surrounding rock, 


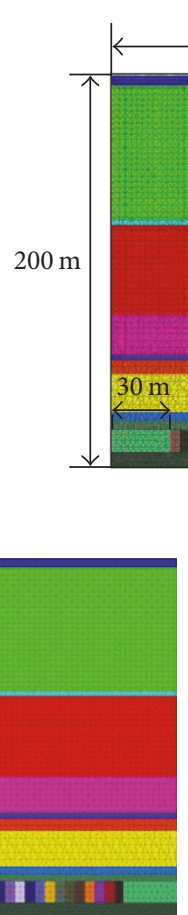

(a) The face's advancing distance is $30 \mathrm{~m}$

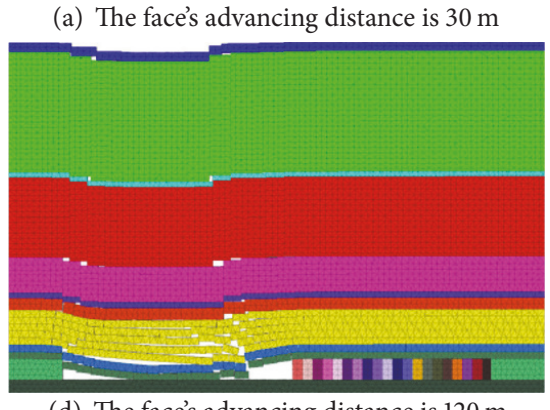

(d) The face's advancing distance is $120 \mathrm{~m}$

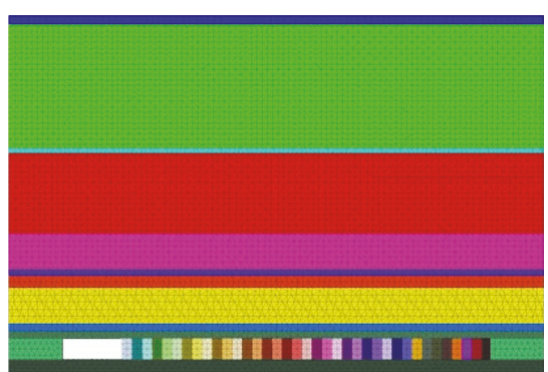

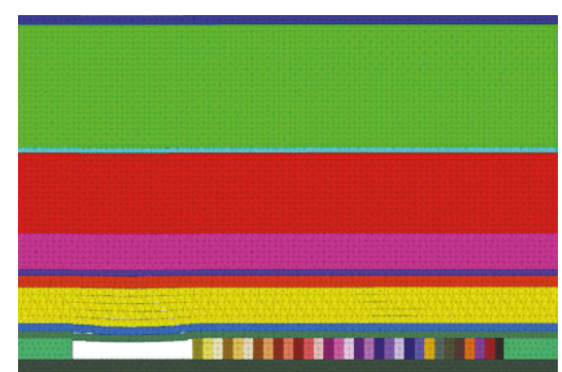

(b) The face's advancing distance is $60 \mathrm{~m}$

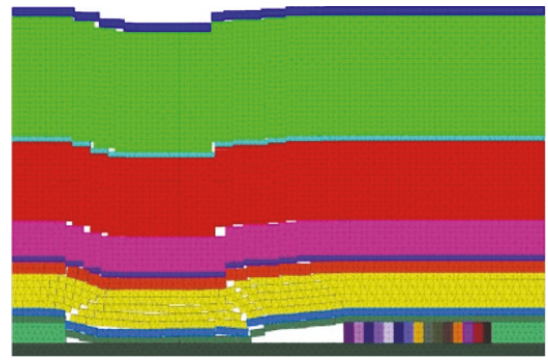

(e) The face's advancing distance is $150 \mathrm{~m}$
Sandstone

Sandy mudstone

Mudstone

Siltstone

Mudstone

4\# coal seam

Siltstone

Lamprophyre

2\# coal seam

Lamprophyre

3-5\# coal seam

Sandstone

Figure 7: The numerical model.

Figure 8: The simulation results.

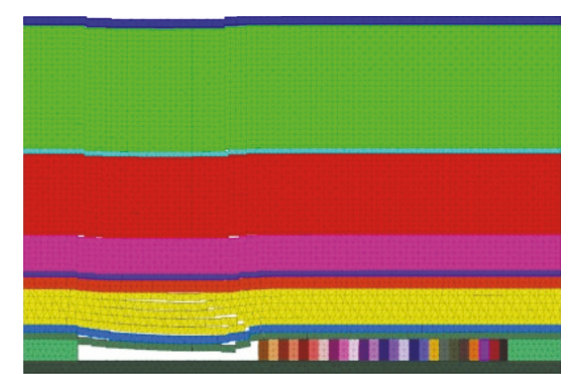

(c) The face's advancing distance is $90 \mathrm{~m}$

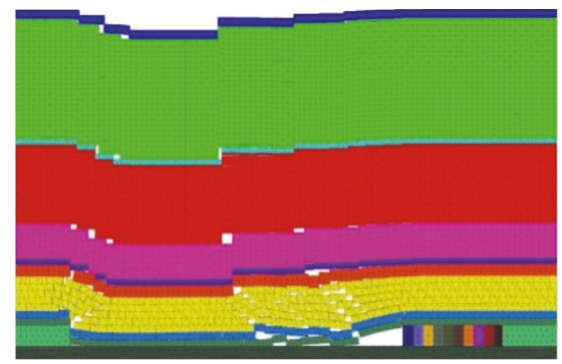

(f) The face's advancing distance is $180 \mathrm{~m}$

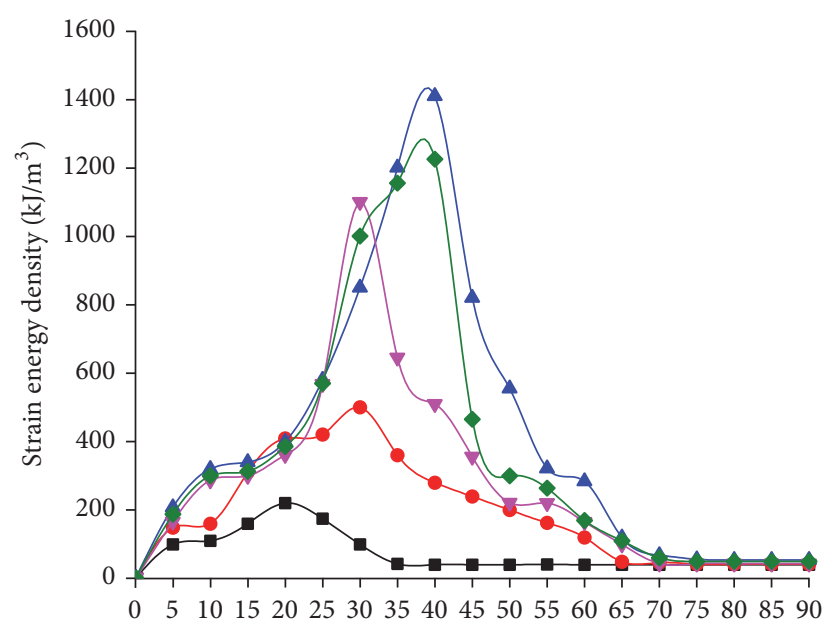

The distance between the measuring points and the working face $(m)$

- The working face's advancing distance is $30 \mathrm{~m}$

- The working face's advancing distance is $60 \mathrm{~m}$

- - The working face's advancing distance is $90 \mathrm{~m}$

$\rightarrow$ The working face's advancing distance is $120 \mathrm{~m}$

$\checkmark$ The working face's advancing distance is $150 \mathrm{~m}$

FIGURE 9: Distribution of strain energy density of coal seam ahead of working face when working face is advancing different distances. 


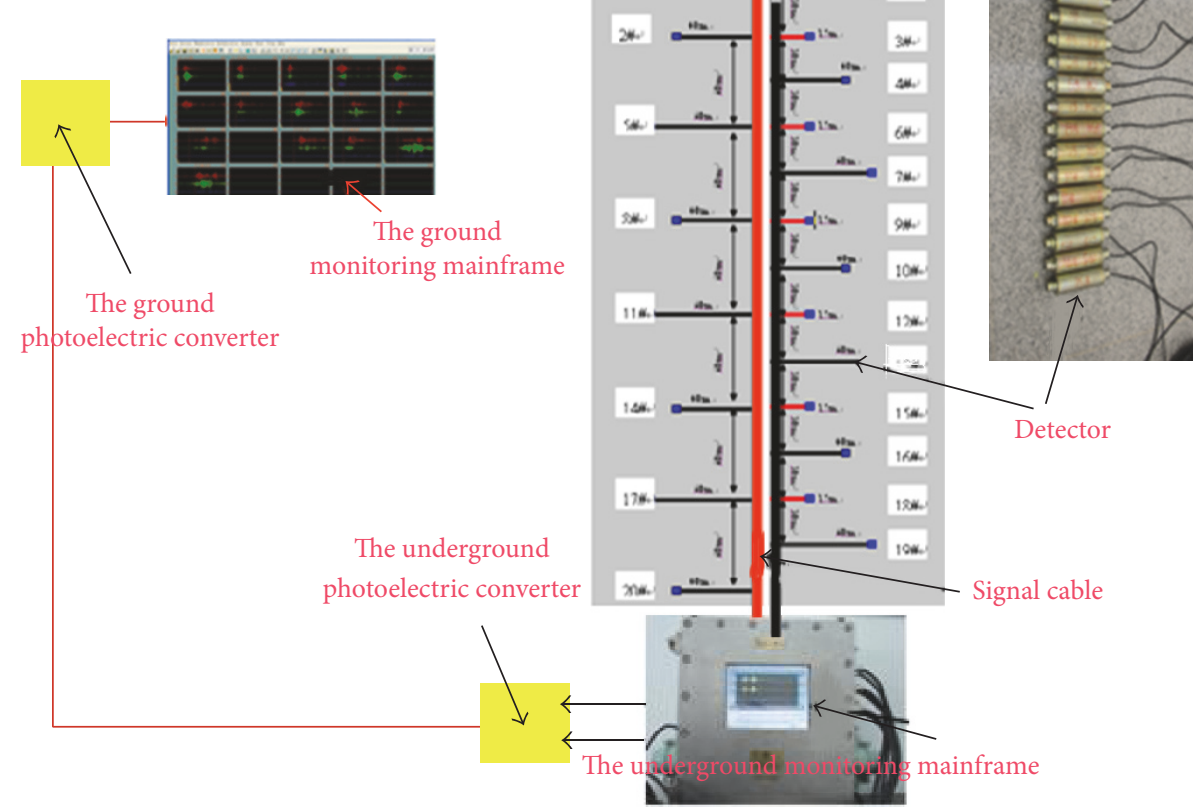

FIGURE 10: Microseismic system.

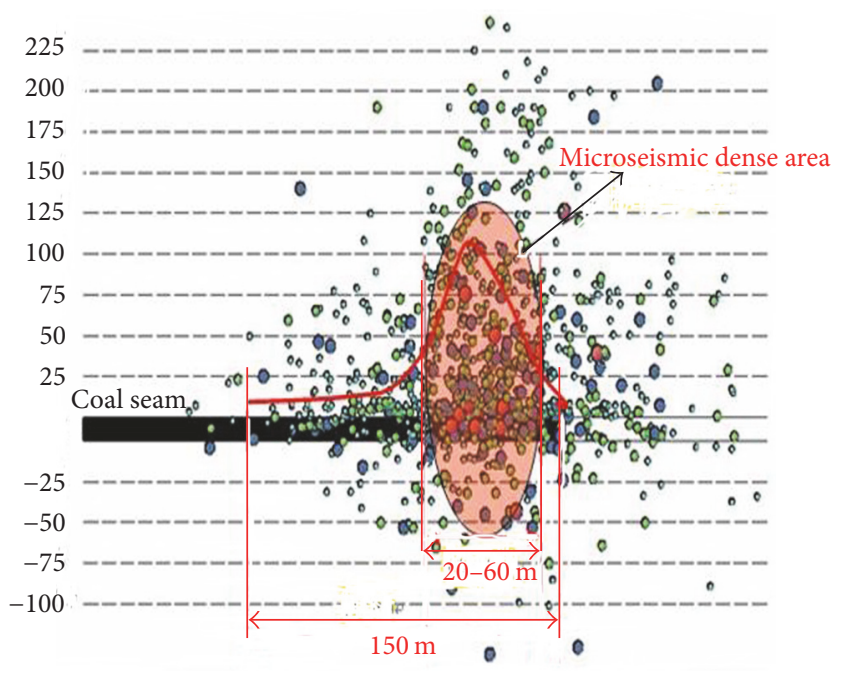

FIGURE 11: Microseismic experiment results.

because a series of dynamic disasters such as coal bumps, rock burst, and mine earthquake are closely related to the gathering and release of strain energy. Therefore, this paper focuses on the distribution of strain energy in coal seam under thick and hard roof action. In the future, we can use the same method combining numerical simulation with theory to get the distribution of strain energy in any region by changing the positions of measuring points. Future studies may involve other energy forms, such as dissipation energy, kinetic energy, and surface energy. And the same research method may help to study other energy forms above, that is, obtaining the parameter values required in the energy expression through numerical simulation and substituting these parameter values into the energy expression to get the specific energy value. In this way, we can avoid the defects that the parameters required in the expression are difficult or even unable to obtain completely in theory.

\section{Conclusions}

(1) Based on Reissner plate theory and combined with weighted residual method, with four-edge fixed condition as the boundary condition, this paper derives the theoretical formula of the first breaking span of thick and hard roof. Based on Vlasov plate theory, with four-edge simply supported condition as the boundary condition, this paper derives theoretical formula of the periodic breaking span of thick and hard roof. The two formulas above are used to calculate the first breaking span and the periodic breaking span of thick and hard roof, respectively, in Tashan Coal Mine, whose results are compared with those of the traditional beam theory. In detail, for 8212 working faces, the error rate is reduced from $34.5 \%$ to $9.69 \%$ when calculating the first breaking span, and the biggest error rate is reduced from $21.6 \%$ to $7.47 \%$ when calculating the periodic breaking span; for 8206 working faces, the error rate is reduced from $38.77 \%$ to $10.2 \%$ when calculating the first breaking span, and the biggest error rate is reduced from $21.3 \%$ to $8.43 \%$ when calculating the periodic breaking span. 
Therefore, the accuracy of the formula deduced in this paper is higher than that of the traditional beam theory when calculating the breaking span of the thick and hard roof.

(2) According to the definition of strain energy density and combined with 3DEC numerical simulation software, this paper studies the distribution of strain energy density of the coal seam in front of the working face with different advance distance. The distribution of the strain energy density in front of the working face is similar to that of the stress distribution, which shows obvious decreasing, increasing, and stable areas. When the thick and hard roof does not break, the strain energy density of the front coal seam at the same distance from the working face increases as the advance distance increases. When the thick and hard roof breaks, energy release leading the strain energy density of the front coal seam at the same distance from the working face decreases firstly and then increases again.

(3) The strain energy accumulated in the coal seam has a good correlation with its microseismic events. That is, when the strain energy of the surrounding rock is large, the probability of occurrence of microseismic events is greater; when the strain energy of the surrounding rock is small, the probability of occurrence of microseismic events is lower. The numerical simulation method helps to study the distribution of surrounding rocks energy in the future.

\section{Conflicts of Interest}

The authors declare that there are no conflicts of interest regarding the publication of this paper.

\section{Acknowledgments}

This study was financially supported by the National Natural Science Foundation of China (51604006) and the National Program on Key Basic Research Project (973 Program) (2010CB226802).

\section{References}

[1] X. N. Shao, Research of fracture law and deep hole advance blasting technology in hard and thick sandstone roof [Ph.D. thesis], Anhui University of Science and Technology, Huainan, China, 2014.

[2] W. Wang, Y.-P. Cheng, H.-F. Wang et al., "Fracture failure analysis of hard-thick sandstone roof and its controlling effect on gas emission in underground ultra-thick coal extraction," Engineering Failure Analysis, vol. 54, pp. 150-162, 2015.

[3] Z. Zheng, Y. Xu, D. Li, and J. Dong, "Numerical analysis and experimental study of hard roofs in fully mechanized mining faces under sleeve fracturing," Minerals, vol. 5, no. 4, pp. 758777, 2015.

[4] H. Shi, Study and application on stability of hard and massive overlying strata in fully mechanized sublevel caving face [Ph.D. thesis], Shandong University of Science and Technology, Qingdao, China, 2005.

[5] M. G. Qian, P. W. Shi, and J. L. Xu, Mining Pressure and Strata Control, China University of Mining and Technology Press, Xuzhou, China, 2010.

[6] B. Zhang and S. Cao, "Study on first caving fracture mechanism of overlying roof rock in steep thick coal seam," International Journal of Mining Science and Technology, vol. 25, no. 1, pp. 133138,2015 .

[7] H. S. Tu, S. H. Tu, F. Chen, C. Wang, and Y. F. Feng, "Study on the deformation and fracture feature of steep inclined coal seam roof based on the theory of thin plates," Journal of Mining Safety Engineering, vol. 31, pp. 49-55, 2014.

[8] J.-A. Wang, J.-W. Zhang, X.-M. Gao, J.-D. Wen, and Y.-D. Gu, "Fracture mode and evolution of main roof stratum above longwall fully mechanized top coal caving in steeply inclined thick coal seam (I) - Initial fracture," Meitan Xuebao/Journal of the China Coal Society, vol. 40, no. 6, pp. 1353-1360, 2015.

[9] J. Fan, L. Dou, H. He et al., "Directional hydraulic fracturing to control hard-roof rockburst in coal mines," International Journal of Mining Science and Technology, vol. 22, no. 2, pp. 177181, 2012.

[10] F. Wang, C. Zhang, X. Zhang, and Q. Song, "Overlying strata movement rules and safety mining technology for the shallow depth seam proximity beneath a room mining goaf," International Journal of Mining Science and Technology, vol. 25, no. 1, pp. 139-143, 2015.

[11] F. Wang, J. Xu, J. Xie, and J. Guo, "Pressure-relief mechanism of lower seam extraction after upper seam extraction," Caikuang yu Anquan Gongcheng Xuebao/Journal of Mining and Safety Engineering, vol. 33, no. 3, pp. 398-402, 2016.

[12] J.-C. Chang, G.-X. Xie, and X.-H. Zhang, "Analysis of rib spalling mechanism of fully-mechanized top-coal caving face with great mining height in extra-thick coal seam," Yantu Lixue/Rock and Soil Mechanics, vol. 36, no. 3, pp. 803-808, 2015.

[13] W. Cai, L. Dou, G. Si, A. Cao, J. He, and S. Liu, "A principal component analysis/fuzzy comprehensive evaluation model for coal burst liability assessment," International Journal of Rock Mechanics and Mining Sciences, vol. 81, pp. 62-69, 2016.

[14] A.-Y. Cao, L.-M. Dou, G.-X. Chen, S.-Y. Gong, Y.-G. Wang, and Z.-H. Li, "Focal mechanism caused by fracture or burst of a coal pillar," Journal of China University of Mining and Technology, vol. 18, no. 2, pp. 153-158, 2008.

[15] J. He, L. Dou, S. Gong, J. Li, and Z. Ma, "Rock burst assessment and prediction by dynamic and static stress analysis based on micro-seismic monitoring," International Journal of Rock Mechanics and Mining Sciences, vol. 93, pp. 46-53, 2017.

[16] X. R. Jia, Rock Mechanics and Strata Control, China University of Mining and Technology Press, Xuzhou, China, 2010.

[17] S. R. Wang, H. H. Jia, and C. F. Wu, "Determination method of roof safety thickness in the mined-out regionsunder dynamic loading and its application," Journal of China Coal Society, vol. 35, pp. 1263-1268, 2010.

[18] G. C. Feng and J. F. Kuai, "Summary of the finite element model:mechanical background and related mathematical problems of various model," Acta Mech Solida Sin, vol. 1, pp. 123-138, 1980.

[19] F. B. He and Y. P. Shen, Theory of plate and shells. Xian Jiaotong, University Press, Xian, China, 1993.

[20] J. Zhao, P. Wang, and Y. Su, "An innovative longwall mining technology in Tangshan coal mine, China," Minerals, vol. 7, no. 1, article no. 14, 2017. 
[21] M. G. Qian and P. W. Shi, Study of Key Strata Theory in Ground Control, China University of Mining and Technology Press, Xuzhou, China, 2003.

[22] Z. Zhang, J. Xu, W. Zhu, and Z. Shan, "Simulation research on the influence of eroded primary key strata on dynamic strata pressure of shallow coal seams in gully terrain," International Journal of Mining Science and Technology, vol. 22, no. 1, pp. 51$55,2012$.

[23] Itasca, "3dec-3-dimensional distinct element code," Itasca Consulting Group, 2013.

[24] C.-P. Lu, L.-M. Dou, N. Zhang et al., "Microseismic frequencyspectrum evolutionary rule of rockburst triggered by roof fall," International Journal of Rock Mechanics and Mining Sciences, vol. 64, pp. 6-16, 2013.

[25] C.-P. Lu, G.-J. Liu, Y. Liu, N. Zhang, J.-H. Xue, and L. Zhang, "Microseismic multi-parameter characteristics of rockburst hazard induced by hard roof fall and high stress concentration," International Journal of Rock Mechanics and Mining Sciences, vol. 76, pp. 18-32, 2015. 


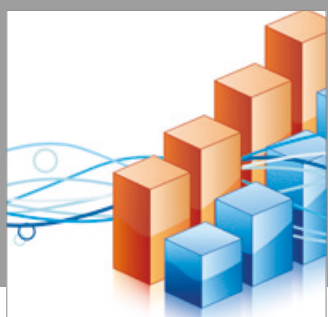

Advances in

Operations Research

vatersals

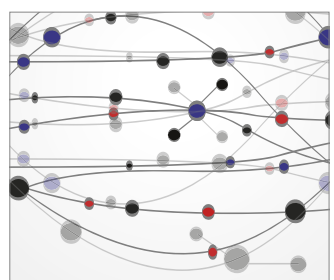

\section{The Scientific} World Journal
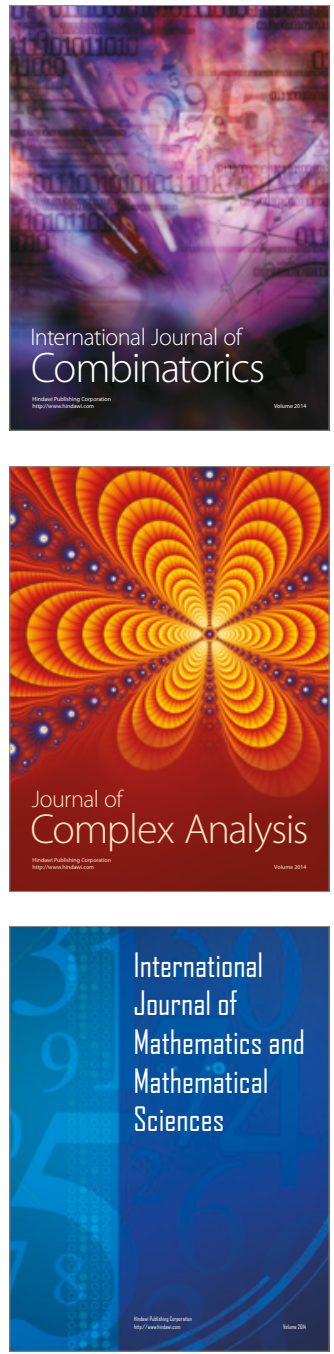
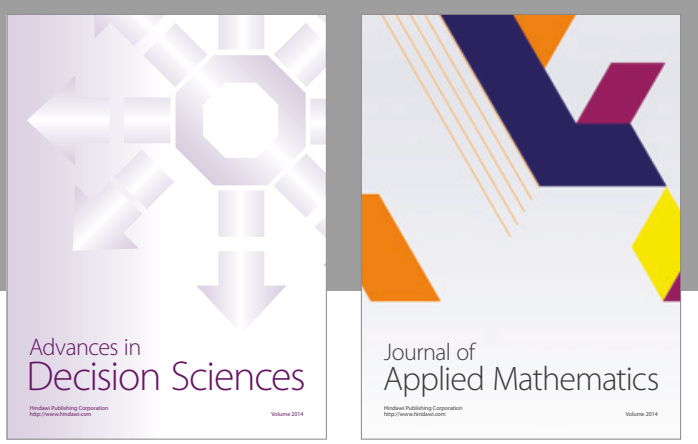

Algebra

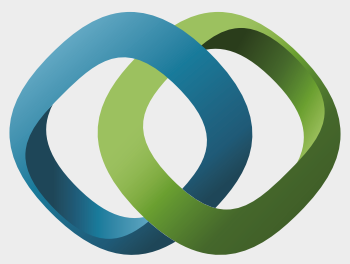

\section{Hindawi}

Submit your manuscripts at

https://www.hindawi.com
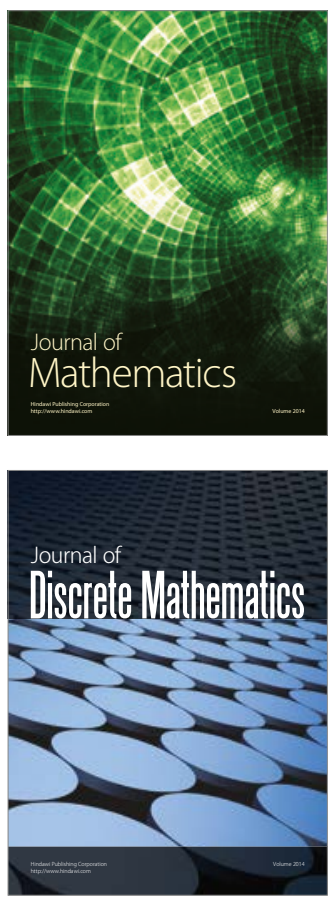

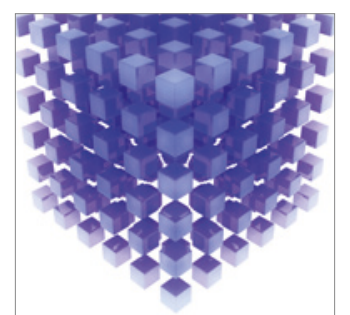

Mathematical Problems in Engineering
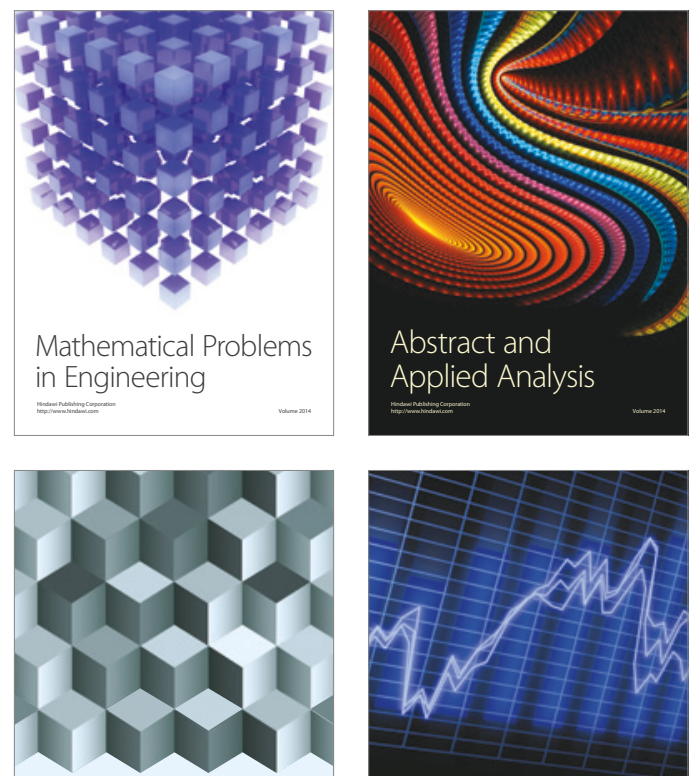

Journal of

Function Spaces

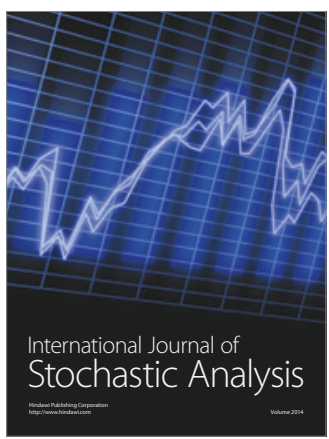

Probability and Statistics
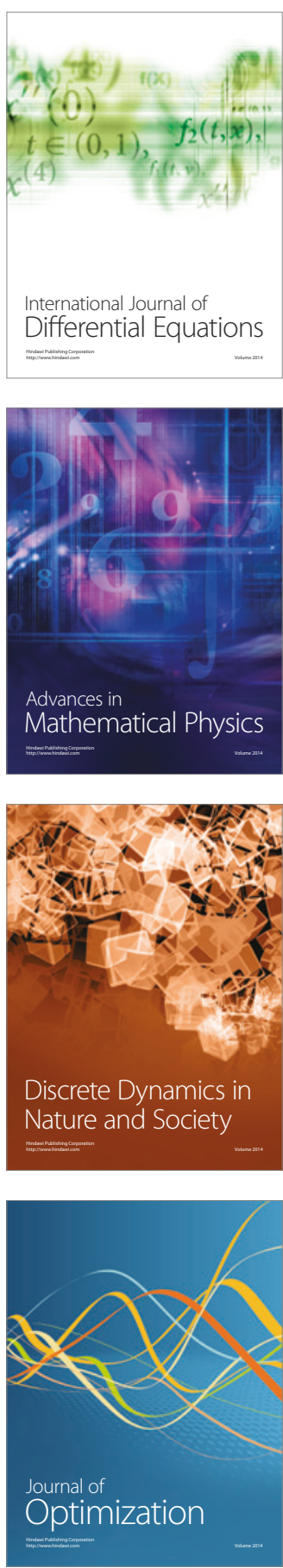